Joseph A. Stirt MD, John R. Shuptrine MD, Cary S. Sternick MD, Gregg A. Korbon MD

\section{Anisocoria after anaesthesia}

administered. Two drops of phenylephrine hydrochloride one per cent topical vasoconstrictor solution were placed into the left nostril. $\mathrm{N}_{2} \mathrm{O}$ was discontinued, and after three minutes of halothane/ $\mathrm{O}_{2}$, succinylcholine $40 \mathrm{mg}$ IV was given. Nasotracheal intubation using direct laryngoscopy was performed via the left nostril without incident. Duratears ${ }^{\circledR}$ sterile ophthalmic ointment* was placed in each eye and the lids were taped shut. The remainder of the $2 \frac{1}{2}$ hour halothane $/ \mathrm{N}_{2} \mathrm{O}$ anaesthetic and operation were unremarkable.

At the end of the procedure, the trachea was extubated and the patient was taken to the recovery room, where she was noted on arrival to be "emerging, crying, and thrashing." Morphine $0.5 \mathrm{mg}$ IV was administered, following which the child became calmer, and asked for her mother.

Thirty minutes after the patient's arrival in the recovery room, the nurse caring for the child noted her left pupil to be $8 \mathrm{~mm}$ in diameter while the right was $4 \mathrm{~mm}$ (Figure), with both reactive to light. The child was awake, and stated she had no headache or eye pain. An ophthalmological examination by the recovery room physician was normal apart from the anisocoria. Consultation with the attending and resident anaesthetists for the patient's anaesthetic procedure revealed that a portion of one drop of one per cent phenylephrine hydrochloride topical vasoconstrictor solution used to prepare the left nostril for intubation had inadvertently splashed off the tip of the patient's nose and entered the left eye at the beginning of the case three hours earlier. No further investigation was undertaken. The pupils were bilaterally equal five hours after beginning anaesthesia, and the patient's recovery was otherwise uneventful.

\section{Discussion}

Anisocoria as a new finding after general anaesthesia with halothane is unusual and disturbing. A

*Alcon Laboratories, Inc., Fort Worth, Texas 76134, U.S.A. 


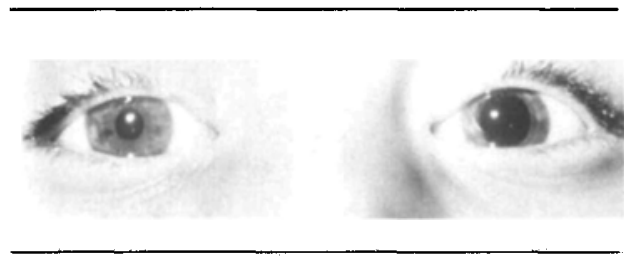

FIGURE Anisocoria $45 \mathrm{~min}$ after emergence from general anaesthesia. The left pupil is $8 \mathrm{~mm}$ in diameter, while the right is $4 \mathrm{~mm}$.

prospective study of the incidence of anisocoria during general anaesthesia found that the majority (59 per cent) of patients receiving diethyl ether had anisocoria, while only 1 of 242 patients receiving halothane developed this sign. ${ }^{1}$ The author proposed that anisocoria during anaesthesia was due to either unequal sensitivity of the pupils to anaesthetic agents and catecholamines liberated during anaesthesia, or to variations in circulation to the pupils or their autonomic nerves. ${ }^{1}$ It is conceivable, if very unlikely, that differential effects of atropine and/or morphine on the autonomic nerves and ganglia of the pupils contributed to the anisocoria in our patient.

Stellate ganglion block produces a Horner's syndrome, including pupillary constriction on the affected side, resulting in anisocoria. Other reports of anisocoria during general anaesthesia have attributed the finding to inadvertent block of the second division of the fifth cranial nerve following injection of local anaesthetic drug, ${ }^{2}$ and to asymmetrically impaired venous return from the face and neck, with resultant venous congestion and exophthalmos. ${ }^{3}$

Anisocoria has been associated with intracranial aneurysm in the unanaesthetized patient, ${ }^{4}$ and thus its presence may be mistaken for a sign of central nervous system deficit. ${ }^{2}$ Transient unilateral pupillary dilation in young adults, often but not always associated with headache, has been reported. ${ }^{5,6}$

In the patient we describe above, general anaesthesia with halothane had been employed, no nerve block had been performed, there was no evidence of venous congestion, nor was there any evident neurological deficit or history of central nervous system dysfunction.

Fibrodysplasia ossificans progressiva, also known as myositis ossificans progressiva or Munchmeyer's disease, is a rare disorder, dominantly inherited, of unknown aetiology. It is characterized by skeletal abnormalities, particularly of the fingers and toes, and ectopic ossification, mainly in the connective tissue of muscle. No central nervous system or eye involvement has been reported in association with this disease. ${ }^{7,8}$ Thus, it is unlikely that the patient we describe had any greater inherent risk of developing anisocoria than any other patient.

No doubt the main factor in the genesis of our patient's anisocoria was the inadvertent deposition of phenylephrine directly into her left eye during application of vasoconstrictor to the left nostril prior to nasal intubation. Phenylephrine is a sympathetic nervous system stimulant acting predominantly on alpha receptors, producing pupillary dilation by causing contraction of the meridional fibres of the iris. Applying ophthalmic ointment and protecting the eyes with tape soon after anaesthesia induction, prior to other manoeuvres, might have prevented the entrance of phenylephrine into the eye. In addition, protection of the eyes as soon as possible after induction of anaesthesia also makes ocular trauma less likely from contact with a variety of foreign objects and substances.

Eye protection prior to the application of vasoconstrictor solution to the nasal mucous membranes may not, however, be totally effective in preventing entrance of such solutions into the eye. Occasionally, anisocoria in awake humans has been seen due to reflux of nasal sympathomimetic drugs from the nose into the eye via the nasolacrimal duct, which permits retrograde flow. ${ }^{9}$ Thus, in the patient we describe above, direct instillation of phenylephrine into the eye, although the main cause, may not have totally accounted for the unilateral mydriasis.

Occurrences such as the one we describe above are not unique, although we were unable to find any other such reports in the literature. Unbeknownst to us at the time, an almost identical sequence of events had occurred in an adult patient in our operating suite two weeks earlier; resolution of that case, however, was accompanied by an emergency neurologic consultation and serious consideration of immediate cerebral arteriography. Perhaps this report will spare other patients (and physicians) the same fate.

The duration of anisocoria in our patient was five hours. An earlier study of the mydriatic effect of one per cent phenylephrine in normal adults showed that half the subjects required nearly three hours to 
recover normal pupillary diameter, the other half requiring longer. ${ }^{10}$ The fact that our patient had green eyes may have contributed to the longer duration required for recovery, since patients with blue, gray, or green eyes have been shown to be more sensitive to mydriatic agents than those with brown eyes. "1

Very little phenylephrine appears needed for pupillary dilation, as only a portion of a drop of one per cent phenylephrine directly entered the eye of the patient we describe. One drop was found to have a volume of approximately $0.03 \mathrm{ml}$, and thus to contain approximately $0.3 \mathrm{mg}$. Standard ophthalmologic mydriatics ( 2.5 and 10 per cent phenylephrine) contain 0.75 and $3.0 \mathrm{mg} / \mathrm{drop}$, respectively.

In summary, a child was found to have anisocoria following an apparently uneventful general anaesthetic. The probable cause was unintended entrance into the eye, both by direct (accidental) instillation and possibly indirectly via the nasolacrimal duct, of phenylephrine vasoconstrictor solution.

\section{References}

1 Sobel $A M$. Anisocoria during general anesthesia. Anesth Analg 1965; 44: 522-6.

2 Holmgreen WC, Baddour HM, Tilson HB. Unilateral mydriasis during general anesthesia. J Oral Surg 1979; 37: 740-2.

3 Klein DS, Kosanin R. Anisocoria and ipsilateral exophthalmos during enflurane ancsthesia. Anesthesiology 1982; 57: 237-8.

4 Payne JW, Adamkiewicz J Jr. Unilateral internal ophthalmoplegia with intracranial aneurysm. Am J Opthalmol 1969; 68: 349-52.

5 Hallett $M, \operatorname{Cogan} D G$. Episodic unilateral mydriasis in otherwise normal patients. Arch Ophthalmol 1970; 84: 130-6.

6 Edelson $R N$, Levy $D E$. Transient benign unilateral pupillary dilation in young adults. Arch Neurol 1974; 31: 12-14.

7 Smith R, Russell RGG, Woods CG. Myositis ossificans progressiva. J Bone It Surg 1976; 58-B: $48-57$.

8 Hentzer B, Jacobsen HH, Asboe-Hansen G. Fibrodysplasia ossificans progressiva. Scand J Rheumatol 1977; 6: 161-71.

9 Stafford TJ. Transient unilateral dilation of pupil associated with headache. JAMA 1972; 221: 1171.
10 Haddad NJ, Moyer NJ, Riley FC Jr. Mydriatic effect of phenylephrine hydrochloride. Am J Ophthal 1970; 70: 729-33.

11 Barbee RF, Smith WO, Jr. A comparative study of mydriatic and cycloplegic agents in human subjects without eye disease. Am J Ophthal 1957; 44: 617-22.

\section{Résumé}

Des pupilles de diamètre inégal après l'anesthésie restent un problème non résolu suggérant une pathologie aigue intracrânienne péri-opératoire. On rapporte le cas d'une cause inhabituelle d'anisocorie après anesthésie: l'entrée involontaire dans l'ail d'une solution de phénylephrine administrée pour vasoconstriction nasale. 